\title{
An ethnobotanical study of medicinal plants administered for the treatment of hypertension
}

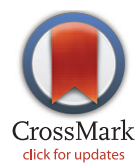

\author{
Babak Baharvand-Ahmadi ${ }^{1}$, Mahmoud Bahmani ${ }^{2}$, Pegah Tajeddini ${ }^{3}$, Mahmoud Rafieian-Kopaei ${ }^{3}$, Nasrollah \\ Naghdi $^{*}$
}

${ }^{1}$ Madani Heart Hospital, Department of Cardiovascular, Faculty of Medicine, Lorestan University of Medical Sciences, Khorramabad, Iran ${ }^{2}$ Clinical Microbiology Research Center, Ilam University of Medical Sciences, Ilam, Iran

${ }^{3}$ Medical Plants Research Center, Shahrekord University of Medical sciences, Shahrekord, Iran

\section{A R T I C L E IN F O}

Article Type:

Original

\section{Article History:}

Received: 9 June 2016

Accepted: 4 August 2016

Published online: 9 August 2016

Keywords:

Ethnobotanical

Hypertension

Medicinal plants

\begin{abstract}
A B S T R A C T
Introduction: The incidence of cardiovascular diseases (CVDs) is very high in human societies and their prevention and treatment are the most important priority in many countries. Hypertension makes an important contribution to the development of CVDs. Objectives: This study aimed to collect the ethno-medicinal knowledge of the traditional healers of Shiraz on medicinal plants used in the treatment of hypertension.

Materials and Methods: Ethno-medicinal data were collected from September 2012 to July 2013 through direct interview. Twenty-five healers were interviewed using semistructured questionnaires and their traditional ethno-medicinal knowledge was recorded. Questionnaires were included apothecary personal information, plant local name, plant parts used, method of preparation, season of harvest and traditional use. Data collected from surveys and interviews were transferred to Microsoft Excel 2007 and analyzed.

Results: Analysis of data showed that, 27 medicinal plants from 22 families are used for the treatment of hypertension. The families with most antihypertensive species were Apiaceae (8\%), Rosaceae (8\%) and Papaveraceae (8\%). The most frequently used plant parts were leaves (36\%) followed by fruits (30\%), aerial part (17\%) and branches (7\%). The most frequently used preparation method was decoction (95\%). Borago officinalis (51.85\%), Berberis vulgaris $(51.58 \%)$ had the highest frequency of mention.

Conclusion: The ethno-medicinal survey of medicinal plants recommended by traditional healers for the treatment of hypertension provides new areas of research on the antihypertensive effect of medicinal plants. In the case of safety and effectiveness, they can be refined and processed to produce natural drugs.
\end{abstract}

Implication for health policy/practice/research/medical education:

Hypertension known as high blood pressure which it is a long-term medical condition in which the blood pressure in the arteries is persistently elevated. Blood pressure is expressed by two measurements, the systolic and diastolic pressures, which are the maximum and minimum pressures, respectively, in the arterial system. In addition to chemical drugs that are commonly prescribed by physicians, there are various ways to comply with them to control the disease, such as exercise, quit smoking, reducing stress and use of medicinal plants in moderation. In our study showed that 27 medicinal plants from 22 families are used for the treatment of hypertension which could have the potential to produce natural remedies for high blood pressure. Please cite this paper as: Baharvand-Ahmadi B, Bahmani M, Tajeddini P, Rafieian-Kopaei M, Naghdi N. An ethnobotanical study of medicinal plants administered for the treatment of hypertension. J Renal Inj Prev. 2016;5(3):123-128. DOI: 10.15171/jrip.2016.26

\section{Introduction}

The incidence of cardiovascular diseases (CVDs) is very high in human societies and their prevention and treatment are the most important priority in many countries. The use of medicinal plants in treatment and prevention of diseases have increased dramatically over the last years (1). High blood pressure can damage vessels of supplying blood to the heart, kidneys, brain, and eyes (2). It makes an important contribution to the development of coronary heart diseases, cardiovascular events and stroke $(2,3)$. The 
overall death rate from hypertension is twice than that of the general population. Hypertension increases the risk of sudden death in patients with CVD. Smoking, hypercholesterolemia and diabetes are important risk factors for the development of hypertension (2).

Hypertension is a major threat to health, especially for older people. Over one-fourth of all death among the elderly people is due to high blood pressure and its complications. It is usually asymptomatic until the development of complications such as heart failure, stroke and kidney failure (3). High blood pressure is referred to as a silent killer (4). In 1997, there were on average 100 million physician office visits for hypertension among adults in the United States (5). Hypertension is the most important risk factor for the development of CVDs. CVDs are the largest cause of death in the developed countries and their prevalence are appears to be increasing in developing countries (6). There are 17 major causes of death in the world and cardiovascular is the seventh leading cause of death. In Iran, CVD is the first line cause of death (7). The cause of high blood pressure is unknown but several factors can contribute to the development of this condition. Obesity and raised body mass index increase the risks of high blood pressure (8). Scientific studies suggested an association between birth weight and blood pressure in children, adolescents and adults. Therefore, detection and control of hypertension is the primary objective for the prevention of CVDs (9).

Several simple methods can be used to control high blood pressure. It can be controlled with lifestyle changes, oral medications or both. So far several drug forms have been introduced to reduce and control high blood pressure, each of them has its own side effects (9). Use of herbal remedies is another way to treat and control hypertension. Medicinal plants are not only effective in the treatment of high blood pressure but also in many other situations (10). However, like other medications, they can lead to unwanted side effects or drug interactions, especially when taken in large doses (11). Vitamins found in vegetables, fruits and fish oil play an important role in the regulation of blood pressure. Thus, consumption of fish and fish oils, carrots, parsley, yellow chicory, apricot, tomato, lettuce, peas, dates and butter that are high in vitamin can be useful in treating hypertension (12). The current trend of medical world is toward using natural compounds in disease prevention and treatment. Medicinal plants, as the most precious gift of Allah to mankind, have long been used in Iranian folk medicine to treat various diseases. This thousand-year-old traditional medicine offers a practical and comprehensive guide for the application of medicinal plants and therefore, following its guidelines can be useful in resolving public health problem (13). Ethno-botanical and ethno-pharmacological surveys are studies intended to document traditional knowledge and use of medicinal plants. They also bring numerous ideas for pharmacological science (14). Recently, a great deal of attention has been focused on the finding of new drugs with minimal side effects and high compatibility with human nature (15). In addition to developing countries, in Western countries especially in Europe, trend toward traditional medicine has been growing despite access to modern medicine (16). Today, pharmaceutical science has made great advances, and herbal medicines are used beside chemical ones to treat various ailments (17). It has been reported that more than $30 \%$ of modern medicines are originally derived from medicinal plants (18). So far, a number of medicinal plants have been investigated for their therapeutic effects (19).

According to the high prevalence of hypertension in the world, especially in Iran and urgent need to discover new effective natural remedies this study aimed to document medicinal plants recommended by Shirazian herbalists for the treatment of hypertension.

\section{Objectives}

This study aimed to collect the ethno-medicinal knowledge of the traditional healers of Shiraz on medicinal plants used in the treatment of hypertension.

\section{Materials and Methods \\ Description of the study area}

Shiraz is one of the major cities in Iran and the capital of Fars province. It is geographically located in the southwest of Iran and in the central of Fars province. The city of Shiraz is situated in the Zagros mountain range, $1468 \mathrm{~m}$ above the sea level and bounded by Drak mountain in the west and Sabzpushan, Bamu, Chelmagham and Babakuhi mountains in the North. Shiraz with a length of $40 \mathrm{~km}$ and a width of 15 to $30 \mathrm{~km}$ has a total area of 1268 square kilometers. Based on the 2009 census the total population of the city was about 1700678 . Generally the city has a moderate climate. The hottest month in Shiraz is July, with an average temperature of 30 and the coldest month is January, with an average temperature of 5 . The average annual temperature is about 18 and the average annual rainfall is $3378 \mathrm{~mm}$.

\section{Ethical issues}

The research followed the tenets of the Declaration of Helsinki. The research was approved by the ethical committee of Shahrekord University of Medical Sciences.

\section{Statistical analysis}

The study was carried out from September 2012 to July 2013. Ethno-Medicinal data was collected from 27 traditional healers through face-to-face interviews. They were interviewed using semi-structured questionnaires and their traditional ethno-medicinal knowledge was recorded. Questionnaires were included apothecary personal information, plant local name, plant parts used, method of preparation, season of harvest and traditional use. Questionnaires data were then transferred to Microsoft Excel 2007 and processed.

Results

Ethno-medicinal information of plants recommended by 
Shirazian herbal healer are shown in Table 1. A total of 27 medicinal plant species belonging to 22 families were recommended by herbal healers for the treatment of hypertension. As shown in Table 2, Borago officinalis (51.85\%), Berberis vulgaris (51.58\%), Anethum graveolens (48.14\%), Coriandrum sativum (44.44\%), Centaurea depressa $M$. (44.44\%), Crataegus aronia (44.44\%), Camellia sinensis (44.44\%), Petroselinum sativum (40.74\%) and Olea europaea $(40.74 \%)$ had the highest frequency of mention. Figure 1 shows plant families recommended by local healer for the treatment of hypertension. The families with most antihypertensive species were Apiaceae (8\%), Rosaceae $(8 \%)$ and Papaveraceae (8\%). Analysis of data showed that leaves $(36 \%)$ were the most frequently used plant parts followed by fruits (30\%), aerial part (17\%) and branches (7\%, Figure 2). As shown in Figure 3, decoction (95\%) was the most frequently used preparation method of medicinal plants.

Figures 1, 2 and 3, respectively show the plant families, Percentage of different plant parts used, and percentage of different preparation methods of medicinal plants for anti-hypertensive plants in the study area.

\section{Discussion}

In this study, we collected ethno-medicinal knowledge from herbal healer in Shiraz for the use of medicinal plants

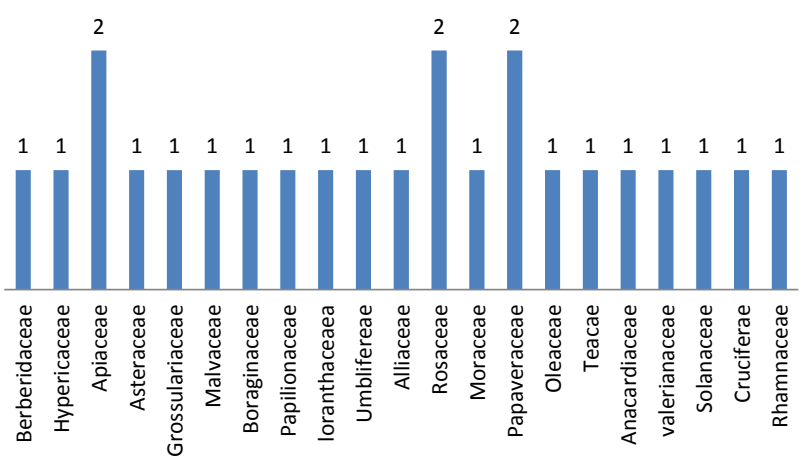

Figure 1. Plant families recommended by local healer for the treatment of hypertension.

as a treatment for hypertension. A total of 27 medicinal plant species belonging to 22 families were documented in the present study for the treatment of hypertension. A wide variety of medicinal plants are used to treat hypertension in different parts of Iran. Rumex crispus $L$ and Ziziphus jujuba (L) H. Karst and Olea europaea L are traditionally used in Mobarakeh of Isfahan (20). In Arasbaran region (Northwestern Iran), Berberis vulgaris L., Achillea millefolium L., Ecballium elaterium, Ribes orientale, Crataegus monogyna, and Taxus baccata $L$ are used to treat high blood pressure (21). In Sistan and Baluchestan prov-

Table 1. Medicinal plants used for the treatment of hypertension; scientific name, common name, family name, plant parts used and preparation methods

\begin{tabular}{|c|c|c|c|c|}
\hline Scientific name & Family & Persian names & Plant parts used & Preparation methods \\
\hline Centaurea depressa $\mathrm{M}$. & Compositae & Golegandom & Seed & Decoction \\
\hline Berberis vulgaris & Berberidaceae & Zereshk & Fruit & Decoction \\
\hline Hypericum perforatum & Hypericaceae & Chay-Koohi & Leave & Decoction \\
\hline Anethum graveolens dhi & Apiaceae & Shevid & Leave & Fresh \\
\hline Coriandrum sativum & Apiaceae & Geshniz & Leave & Fresh \\
\hline Cichorium intybus $L$ & Asteraceae & Kasni & Leave & Decoction \\
\hline Ribes divaricatum & Grossulariaceae & Angoor & And Fruit Leave & Fresh \\
\hline Althea aucheri Boiss. & Malvaceae & Khatmi-Armanestani & Aerial parts & Decoction \\
\hline Borago officinalis & Boraginaceae & Gavzaban & Fruit & Decoction \\
\hline Gundelia tournefortii $L$. & Compositae & Kangar & Leave & Fresh \\
\hline Trigonella monspeliaca & Papilionaceae & Shanbalileh-Monileei & Leave and Fruit & Fresh \\
\hline Viscum album & Loranthaceae & Darvash & Aerial parts & Decoction \\
\hline Petroselinum sativum & Umbelliferae & Jafari & Leave & Fresh \\
\hline Allium sativum & Alliaceae & Sir & Bulb & Fresh \\
\hline Crataegus aronia & Rosaceae & Zalzalak & Fruit & Fresh \\
\hline Ficus religiosa & Moraceae & Anjir & Fruit & Fresh \\
\hline Glaucium oxylobum Boiss \& Buhse & Papaveraceae & Shaghayegh-Goltiz & Leave & Decoction \\
\hline Glaucium grandiflorum Boiss \& Huet. & Papaveraceae & Shaghayegh-Goldorosht & Leave & Decoction \\
\hline Olea europaea & Oleaceae & Zeytoon & Leave and Fruit & Decoction \\
\hline Camellia sinensis & Teacae & Chay-sabz & Leave & Decoction \\
\hline Rhus Coriaria. $L$ & Anacardiaceae & Somagh & Fruit & Decoction \\
\hline Matricaria recutita & Asteraceae & Babooneh & Flower & Decoction \\
\hline Valeriana officinalis & valerianaceae & Sonboletib & Aerial parts & Decoction \\
\hline Cotoneaster persica Pojark. & Rosaceae & Shirkhest & Aerial parts & Decoction \\
\hline Physalis alkekengi & Solanaceae & Aroosak-Poshtpardeh & Aerial parts & Decoction \\
\hline Descurainia Sophia (L.) Schr. & Cruciferae & Khakshir Irani & Fruit & Fresh \\
\hline Ziziphus zizyphus & Rhamnaceae & Annab & Fruit & Fresh \\
\hline
\end{tabular}


Table 2. Frequency of mentions of anti-hypertensive effects for each plant spices

\begin{tabular}{|c|c|c|c|}
\hline Scientific name & Persian name & $\begin{array}{c}\text { The number of herbalists } \\
\text { mentioned the plant }\end{array}$ & $\begin{array}{c}\text { Frequency of citation } \\
\text { (FC) percentage (\%) }\end{array}$ \\
\hline Centaurea depressa $M$. & Golegandom & 12 & 44.44 \\
\hline Berberis vulgaris & Zereshk & 14 & 51.58 \\
\hline Hypericum perforatum & Chayekohi & 6 & 22.22 \\
\hline Anethum graveolens dhi & Shevid & 13 & 48.14 \\
\hline Coriandrum sativum & Geshniz & 12 & 44.44 \\
\hline Cichorium intybus $L$ & Casni & 10 & 37.03 \\
\hline Ribes divaricatum & Angoor & 13 & 48.14 \\
\hline Althea aucheri Boiss. & Khatmi-Armanestani & 9 & 33.33 \\
\hline Borago officinalis & Gavzaban & 14 & 51.85 \\
\hline Gundelia tournefortii $L$. & Kangar & 5 & 18.51 \\
\hline Trigonella monpeliaca & Shanbalileh-Monilileei & 7 & 25.92 \\
\hline Viscum album & Darvash & 5 & 18.51 \\
\hline Petroselinum sativum & Jafari & 11 & 40.74 \\
\hline Allium sativum & Sir & 10 & 37.03 \\
\hline Crataegus aronia & Zalzalak & 12 & 44.44 \\
\hline Ficus religiosa & Anjir & 3 & 11.11 \\
\hline Glaucium oxylobum Boiss \& Buhse & Shaghayegh-Labtiz & 1 & 3.70 \\
\hline Glaucium grandiflorum Boiss \& Huet. & Shaghayegh-Goldorosht & 2 & 7.40 \\
\hline Olea europaea & Zeytoon & 11 & 40.74 \\
\hline Camellia sinensis & Chay-Sabz & 12 & 44.44 \\
\hline Rhus Coriaria . L & Somagh & 4 & 14.81 \\
\hline Matricaria recutita & Babooneh & 5 & 18.51 \\
\hline Valeriana officinalis & Sonboletib & 5 & 5 \\
\hline Cotoneaster persica Pojark. & Shirkhesht & 4 & 14.81 \\
\hline Physalis alkekengi & Aroosak-poshtpardeh & 4 & 14.81 \\
\hline Descurainia Sophia (L.) Schr. & Khakshir-Irani & 3 & 3 \\
\hline Ziziphus zizyphus & Annab & 1 & 3.70 \\
\hline
\end{tabular}

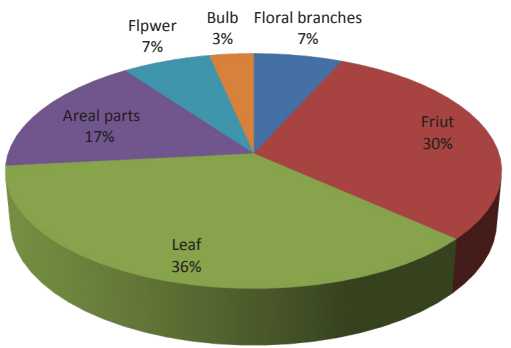

Figure 2. Percentage of different plant parts used to treat hypertension in the study area.

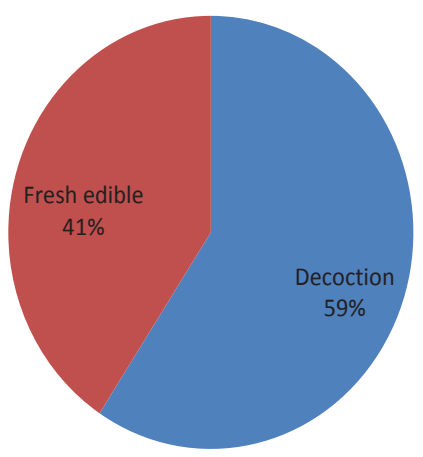

Figure 3. Percentage of different preparation methods of medicinal plants in the study area. ince, Nigella (Nigella sativa L.) is used for this purpose (22). Silybum marianum (L.) Gaerth, Achillea tenuifolia, Cichorium intybus, Silybum marianum, Berberis vulgaris, Capsella bursa-pastoris, Equisetum arvense, Juglans regia, and Melilotus indicus are used in Kazerun (Southern Iran) to treat hypertension (23). In Lorestan province, Falcaria vulgaris, Smyrnium cordifolium, Crocus haussknechtii, Berberis integerrima, Ziziphus spina-christi, Ziziphus nummularia, Allium ursinum, Tragopogon porrifolius, Anethum graveolens are thought to have blood pressure lowering effect (24). Rheum ribes L. and Paliurus spina-christi are used to lower blood pressure in Ilam province (25). Comparison of medicinal plants used for treating hypertension in different parts of Iran shows that different cultures and cities of Iran use different plants to treat hypertension however, some common plants are also used in different area. In this study, several plant species were documented for the first time to treat hypertension and may have the potential to produce antihypertensive drugs.

The exact mechanisms responsible for the anti-hypertensive effect of medicinal plants are not fully understood and needed to be investigated. As mentioned, several factors and conditions can lead to increased blood pressure level (12). Several findings suggest that increased oxidative stress potentially contribute to the elevation of blood pressure level (6). Antioxidant activity is one of the most 
important biological effects of medicinal plants and this effect is mainly attributed to the presence of secondary metabolites, especially phenolic compounds. Therefore, the hypertensive effect of medicinal plans may be related to the attenuation oxidative stress. Thus, it can be said that other medicinal plants with antioxidant effects may be effective in the treatment of hypertension.

\section{Conclusion}

The ethno-medicinal survey of medicinal plants recommended by traditional healers for the treatment of hypertension provides new areas of research on the antihypertensive effect of medicinal plants. In the case of safety and effectiveness, they can be refined and processed to produce natural drugs.

\section{Limitations of the study}

This study was limited to a part of Iran. The same study in various parts of Iran is suggested.

\section{Acknowledgments}

The authors accomplish this research by the support of Shahrekord University of Medical Sciences, Shahrekord, Iran (Grant\# 9/7995).

\section{Authors' contribution}

All the authors wrote the first draft of the manuscript equally. MRK revised and edited the last version.

Authors declare no conflict of interests.

\section{Conflicts of interest}

Authors declare no conflict of interests.

\section{Ethical consideration}

Ethical issues (including plagiarism, data fabrication, double publication) have been completely observed by authors.

\section{Funding/Support}

None.

\section{References}

1. Cooper DH, Krainik AJ, Lubner SJ. The Washington manual of medical therapeutics. 32nd ed. New York, Lippincott Williams \& Wilkins; 2007.

2. Staessen JA, Fagard R, Thijs L, Celis H, Arabidze GG, Birkenhäger $\mathrm{WH}$, et al. Randomised doubleblind comparison of placebo and active treatment for older patients with isolated systolic hypertension. The Systolic Hypertension in Europe (Syst-Eur) Trial Investigators. Lancet. 1997;350:757-64.

3. Sarrafzadegan N, Khosravi-Boroujeni H, Esmaillzadeh A, Sadeghi M, Rafieian-Kopaei M, Asgary S. The association between hypertriglyceridemic waist phenotype, menopause, and cardiovascular risk factors. Arch Iran Med. 2013;16:161-6.

4. Alter M, Friday G, Lai SM, O'Connell J, Sobel E. Hypertension and risk of stroke recurrence. Stroke.
1994;25:1605-10.

5. Vasan RS, Larson MG, Leip EP, Evans JC, Donnell CJ, Kannel WB. Impact of high -normal blood pressure on the risk of cardiovascular disease. $\mathrm{N}$ Engl J M. 2001;345:1291-7.

6. Meyers DG, Strickland D, Maloley PA. Possible association of a reduction in cardiovascular events with blood donation. Heart. 1997;78:188-93.

7. Sadeghpour S, Faghihimani E, Hassanzadeh A, Amini M, Mansourian M. Predictors of all-cause and cardiovascular-specific mortality in type 2 diabetes: A competing risk modeling of an Iranian population. Adv Biomed Res. 2016; 5:82. doi: 10.4103/2277-9175.182213.

8. Rurik I, Nagy K, Antal M. Correlation of anthropometric parameters and blood pressures in elderly people. ORV Hetil. 2004;145:1237-41

9. 1999 World Health Organization-International Society of Hypertension Guidelines for the Management of Hypertension. Guidelines Subcommittee. J Hypertens. 1990;17:151-83.

10. Rahnama S, Rabiei Z, Alibabaei Z, Mokhtari S, RafieianKopaei M, Deris F. Anti-amnesic activity of Citrus aurantium flowers extract against scopolamine-induced memory impairments in rats. Neurol Sci. 2015;36:55360. doi: 10.1007/s10072-014-1991-2.

11. Nasri H, Shirzad H. Toxicity and safety of medicinal plants. J HerbMed Plarmacol. 2013;2:21-2.

12. Gholami-Ahangaran M, Bahmani M, Zia-Jahromi N. Comparative and evaluation of anti-leech (Limnatis Nilotica) effect of Olive (Olea Europaea L.) with levamisol and tiabendazole. Asian Pac J Trop Dis. 2012;2:S101-3.

13. Asadi-Samani M, Bahmani M, Rafieian-Kopaei $M$. The chemical composition, botanical characteristic and biological activities of Borago officinalis: a review. Asian Pac J Trop Med. 2014;7:22-8.

14. Asadbeigi M, Mohammadi T, Rafieian-Kopaei M, Saki K, Bahmani M, Delfan B. Traditional effects of medicinal plants in the treatment of respiratory diseases and disorders: an ethnobotanical study in the Urmia. Asian Pac J Trop Med. 2014;7:S364-8.

15. Karamati SA, Hassanzadazar H, Bahmani M, RafieianKopaei M. Herbal and chemical drugs effective on malaria. Asian Pac J Trop Dis. 2014;4:599-601.

16. Delfan B, Kazemeini HR, Bahmani M. Identifying effective medicinal plants for cold in Lorestan province, West of Iran. J Evid Based Complementary Altern Med. 2015;20(3):173-9. doi: 10.1177/2156587214568458.

17. Sarrafchi A, Bahmani M, Shirzad H, Rafieian-Kopaei M. Oxidative stress and Parkinson's disease: new hopes in treatment with herbal antioxidants. Curr Pharm Des. 2016;22:238-46.

18. Bahmani M, Forouzan SH, Fazeli-Moghadam E, Rafieian-Kopaei M, Adineh A, Saberianpour SH. Oak (Quercus branti): an overview. J Chem Pharm Res. 2015;7:634-9.

19. Shayganni E, Bahmani M, Asgary S, Rafieian-Kopaei M. Inflammaging and cardiovascular disease: management by medicinal plants. Phytomedicine. 2015. pii: S09447113(15)00356-6. doi: 10.1016/j.phymed.2015.11.004.

20. Mardani-Nejhad S, Vazirpour M. Ethno-botany of 
medicinal plants by Mobarakeh's people (Isfahan). J Herbal Drugs. 2012;3:111-26.

21. Zolfaghari A, Adeli A, Mozafarian V, Babaei S, HabibiBibalan G. Identification of medicinal plants and indigenous knowledge of local people Arasbaran. J Med Arum Plants. 2013;28:534-50.

22. Iranmanesh M, Najafi S, osefi M. Studies on Ethnobotany of important medicinal plants in Sistan. J Herbal Drugs. 2010;1:58-65.

23. Khodayari H, Amani SH, Amiri H. Ethnobotanical study of North east of Khuzistan province. Ecophytochem J
Med Plants. 2013;4;12-26.

24. Delfan B, Saki K, Bahmani M, Rangsaz N, Delfan M, Mohseni N, et al. A study on anti-diabetic and antihypertension herbs used in Lorestan province, Iran. J Herbmed Pharmacol. 2014;3:71-6.

25. Ghasemi Pirbalouti A, Momeni M, Bahmani M. Ethnobotanical study of medicinal plants used by kurd tribe in dehloran and abdanan districts, Ilam province, Iran. Afr J Tradit Complement Altern Med. 2013;10:368-85.

Copyright $\odot 2016$ The Author(s); Published by Nickan Research Institute. This is an open-access article distributed under the terms of the Creative Commons Attribution License (http://creativecommons.org/licenses/by/4.0), which permits unrestricted use, distribution, and reproduction in any medium, provided the original work is properly cited. 